\title{
Responsabilidade do Cirurgião Dentista Frente ao Código de Defesa do Consumidor.
}

\section{Responsibility of the Surgeon Dentist Accord to the Code of Defense of the Consumer.}

\section{Enio Figueira Junior ${ }^{1}$ \\ Giselle de Oliveira Trindade ${ }^{2}$}

\author{
Palavras-chave: \\ Responsabilidade \\ Cirurgião-dentista
}

Reparação

Resumo
Esta revisão bibliográfica tem como objetivo central o esclarecimento do tópico 'responsabilidade civil 'de um profissional liberal, aqui especificamente o cirurgião-dentista (CD), das sanções a que ele está sujeito no exercício de sua profissão perante à legislação atual; havendo breves comentários também do código de defesa do consumiodor. Este código coloca o CD como aquele que deve provar que se utilizou de todo o conhecimento e técnica para a execução de seu trabalho.

A Responsabilidade Civil leva à obrigação de reparação do dano. As conseqüências advindas daí serão posteriormentes analisadas à luz da justiça com o objetivo de gradação da penalidade a ser imposta. Na esfera odontológica, o Código de ética Odontológica também obriga o CD à reparação dos atos profissionais em desacordo com os preceitos técnicos necessários a sua execução.. Quando analisada sob o aspecto legal, a Responsabilidade dos Cirurgiões- dentistas deve ser tratada observando-se uma duplicidade de enfoque. A primeira, enfatiza a obrigação que tem o cirurgião dentista em assumir a responsabilidade e aceitar as consequências oriundas de seus atos profissionais praticados; e, a segunda, do fato desta responsabilidade poder gerar ou produzir uma imposição legal derivada de ato ilícito, a qual consiste em satisfazer o paciente (cliente), inclusive com uma quantia pecuniária ou uma indenização financeira fixada em procedimento judicial, a qualquer dano, prejuízo ou perda que eventualmente venha ocasionar ao paciente. $\mathrm{O}$ ato ilícito na área da odontologia, poderá gerar diversas consequências distintas, todas previstas no Código de Ética Odontológica. Evidentemente, além destas sanções ditadas pelo Código de Ética, o profissional também poderá sofrer punições mais severas, regulamentadas pelo Código de Defesa do Consumidor, amparadas por preceitos constitucionais, tais como artigo $5^{\circ}$, caput; incisos I, II, XIII, XXXII, XXXV, LIII, LV, LVI, LVII.
Abstract

This bibliographical revision has as central objective the explanation of the topic 'responsibility civil' de a liberal professional, here specifically the surgeon-dentist (CD), of the sanctions the one that he is subject in the exercise of his/her profession before to the current legislation; having brief comments also of the code of defense of the consumiodor. This code puts the CD as that that should prove that it was used of the whole knowledge and technique for the execution of his/her work.

The Civil Responsibility takes to the obligation of repairing of the damage. The consequences advindas then will be posteriormentes analyzed to the light of the justice with the gradation objective of the penalty to be imposed. In the sphere odontológica, the ethics Code Odontológica also forces the $C D$ to the repairing of the professional actions in disagreement with the necessary technical precepts his/her execution.. When analyzed under the
Key words:

Responsibility

Surgeon-dentist

Repair
Artigo

Original

Original

Paper

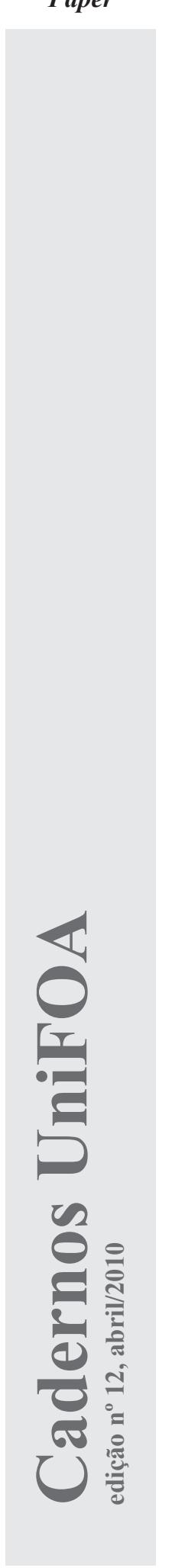

${ }^{1}$ Cirurgião-dentista e Bacharel em Direito; Mestre em Ciências; professor da disciplina de Odontologia Legal e Deontologia da Faculdade de Odontologia de Valença; e professor de Medicina Legal e Deontologia da Faculdade de Direito de Valença; professor de Clínica Integrada do UNIFOA

${ }^{2}$ Cirurgiã-dentista e acadêmica da Faculdade de Direito de Valença. 
legal aspect, the Responsibility of the Surgeons - dentists should be treated being observed a focus duplicity. The first, emphasizes the obligation that has the surgeon dentist in to assume the responsibility and to accept the consequences originating from of their practiced professional actions; and, Monday, of the fact of this responsibility to generate or to produce a derived legal imposition of illicit action, which consists of satisfying the patient (customer), besides with a financial amount or a financial compensation fastened in judicial procedure, the any damage, damage or loss that eventually comes to cause the patient. The illicit action in the area of the dentistry, it can generate several different consequences, all foreseen in Ética Odontológica's Code. Evidently, besides these sanctions dictated by the Code of Ethics, the professional will also be able to suffer more severe punishments, regulated by the Code of Defense of the Consumer, aided by constitutional precepts, such as article $5^{\circ}$, caput; and I, II, XIII, XXXII, XXXV, LIII, LV, LVI, LVII specific points.

\section{Introdução}

Sobre a atividade do dentista, não ocorre uma unanimidade de opinião entre as manifestações de legisladores e juristas em ser classificada como sendo um resultado de meio ou de obrigação. Mas a grande parte de nossos juristas entende que, ao contrário dos procedimentos do campo da medicina, para maior parte dos tratamentos odontológicos, é possível prever um resultado final. Dessa forma, tais tratamentos recaem, como regra, em obrigações de resultados, tendo o dentista, além dos deveres de empregar todo zelo necessário ao exercício de seu ofício e de utilizar os recursos de sua profissão, também, a obrigação de garantir um fim esperado pelo paciente.

A Ação de Responsabilidade Civil, objetiva basicamente comprovar a ocorrência de um dano, bem como a fixação, pela autoridade julgadora, de uma determinada quantia pecuniária indenizatória, com a finalidade de gerar uma reparação do dano ocasionado, seja ele material, físico ou moral.

O termo "Responsabilidade civil", em sua denominação jurídica, trata-se da obrigação em que se encontra $o$ agente, de responder por seus atos profissionais e de sofrer suas consequências. Caio Mario(2007), entende como a efetivação da Responsabilidade abstraída do dano em relação a um sujeito passivo da relação jurídica que se forma.

O termo responsabilidade é definido como:

"o dever jurídico de responder pelos próprios atos e os de outrem, sempre que estes atos violem os direitos de terceiros protegidos pelas leis, assim como o de reparar os danos causados, objetivando uma indenização". (CAVALIERI S. F, 2007, p. 23).

Dessa forma, a indenização implica ressarcir a vítima dos prejuízos sofridos, buscando o seu restabelecimento e procurando reconduzi-la a uma situação idêntica ou pelo menos, a mais próxima possível, em que ela encontrava-se antes da ocorrência do dano ou da lesão. Consequentemente, o paciente será recompensado pelos gastos com medicamentos, exames complementares, eventuais tratamentos paralelos, possíveis internações hospitalares ou mesmo cirurgias reparadoras. $\mathrm{O}$ valor da indenização será discutido e estabelecido durante a fase de instrução do processo e, de acordo com sua complexidade, poderá a autoridade julgadora socorrer-se de trabalhos periciais, o que, justifica, pelo menos em parte, as altas importâncias indenizatórias fixadas pelos Tribunais.

A Complexidade se dá ao fixar um valor de mensuração para o ressarcimento do dano moral, pois como transmite Washington de Barros:

\footnotetext{
“do dano moral não há ressarcimento, já que é praticamente impossível restaurar o bem lesado, tem caráter imaterial. Resulta, na maior parte das vezes, da violação de um direito da personalidade: vida, integridade física, honra, liberdade etc." (BARROS, W. 2003, pág. 481).
}

A Lei pode impor uma indenização baseada em dois critérios para a fixação, que 
são a compensação ao lesado e o desestímulo ao lesante, pretendendo dessa forma que a satisfação do dinheiro possa minimizar os sentimentos feridos, possibilitando o acesso a bens ou serviços, sejam materiais ou espirituais. Contudo, para a fixação do dano moral como quantia, os tribunais baseiam-se na quantia de cinco a cem salários mínimos. Dentre outros, também se costuma utilizar em base o máximo de 200 salários mínimos. Outros fatores, de ordem agravantes ou atenuantes, podem também, fazer com que o valor fixado seja alterado para mais ou para menos. Entre estes, destacam-se a capacidade moderadora do julgador, que analisará evidentemente todas as circunstâncias do caso como a idade e sexo da vítima, extensão da lesão e eventuais sequelas e as situações financeiras da vítima e do ofensor.

Assim, por exemplo, na existência de um seguro, este fato poderá ser relevante no estabelecimento do "quantum" indenizatório.

Deverá ser levado em consideração que, os danos morais, embora indenizáveis, não pode constituir-se em fonte de enriquecimento do lesado às custas do lesor. Por outro lado, não pode ser em valor insignificante, pois deve servir de reprimenda para evitar a repetição da conduta lesiva.

Para que a função protetiva do Direito seja eficaz, a pessoa deve ser amparada em seus interesses materiais e morais, quando existir uma ação ou omissão lesiva a estes interesses, surge, então, a necessidade de reparação dos danos acarretados ao lesado.

A fonte da Responsabilidade Civil consiste no interesse de restabelecer o equilíbrio violado pelo dano.

A teoria de Responsabilidade Civil segundo Washington de Barros:

\footnotetext{
"visa ao restabelecimento da ordem ou equilíbrio pessoal e social, por meio da reparação dos danos morais e materiais oriunda da ação lesiva a interesse alheio, único meio de cumprir-se a finalidade do direito, que é viabilizar a vida em sociedade, dentro do conhecido ditame de "neminem laedere.". (BARROS, W. 2003, pág. 448)
}

\section{Responsabilidade do Cirurgião-Dentista, Condutas Admissíveis ao Código de Ética Odontológica.}

Especificamente no que se refere à responsabilidade civil, o solicitante ou credor da obrigação será sempre uma pessoa determinada, neste caso, representada pelo paciente. A vítima ou o devedor será o profissional liberal; este podendo ser tanto uma pessoa física como jurídica ( empresa ou clínica prestadora de serviços odontológicos ).

Para a materialização da responsabilidade do cirurgião-dentista, existe a necessidade da ocorrência concomitante de cinco condições: A primeira requer o agente, que necessariamente deverá ser um cirurgião-dentista legalmente habilitado, não ficando, entretanto, isentos de penas, aqueles que participam de práticas ilegais. $\mathrm{O}$ ato profissional, que pode ser ele por ação ou omissão, é a segunda condição para que ocorra a materialização; tais atos obedecem às normas e dispositivos específicos da Legislação. Terceiro elemento: deve haver ausência de dolo, pressupõe, portanto, que o profissional não haja com má fé, engano ou traição; em outras palavras, trata-se de uma culpa profissional praticada sem a intenção de prejudicar, nas condições consagradas juridicamente nas suas três espécies da imprudência, negligência ou imperícia. A existência de dano compõe o quarto elemento, e nesse sentido, para que o profissional seja responsabilizado civilmente por uma atitude ou um procedimento que seja tipificado como ilegal, será necessário, então, que haja a ocorrência de uma consequência danosa ou um prejuízo para seu paciente. Por fim, como quinta condição, a relação, ou nexo, entre causa e efeito.; e segundo esta condição, o profissional só será autuado como responsável, se for constatada uma relação direta ou indireta entre $\mathrm{o}$ ato profissional e o dano produzido. O nexo causal é, portanto, a configuração de que, sem a ação ou a omissão do profissional, não haveria ocorrido o prejuízo ou o dano ao paciente

Se no passado, o dever de reparar o dano cometido recaía sobre a pessoa que o tinha praticado, sob a forma de vingança individual, com a evolução da humanidade e consequente 
valorização da ética e da vida humana, o dever de ressarcimento do dano, prejuízo ou injúria cometida passou a recair sobre o patrimônio e bens da pessoa infratora.

Pelo Código de Ética Odontológica são estabelecidas regras de condutas, moralidade e ética do profissional, que se infringidas podem gerar um ato ilícito praticado em ofensa à lei, à ética, à moral ou aos bons costumes - do qual pode resultar dano a outrem. A prática do ato ilícito gera para seu autor a obrigação de repará-lo. Um ato ilícito ocorre quando, o dentista que fracassa em um determinado tratamento aplicado a um paciente, por ausência de um diagnóstico correto e tão completo quanto necessário para o respectivo ato a ser executado.

Entretanto, o ato ilícito pode ocorrer não só como consequência de uma ação lesiva ao paciente, mas também por omissão, quando o profissional que tinha o dever de praticar determinado ato e, por negligência, deixa de fazê-lo.

Mesmo quando o profissional não respeita o sigilo das informações fornecidas pelo paciente, é previsto no Código de Ética Odontológica: "Art. $9^{\circ}$ Constitui infração ética: I - revelar, sem justa causa, fato sigiloso de que tenha conhecimento em razão do exercício de sua profissão".

Além de preconizar a ética e a moral, o Código de Ética Odontológica, em seus $\operatorname{artigos} 3^{\circ}$ e $4^{\circ}$, preconiza que entre os deveres/ direitos fundamentais dos dentistas destacamse: comportar-se dignamente; zelar não só pela saúde, mas também pela dignidade do paciente; manter-se atualizado com os conhecimentos científicos e profissionais; diagnosticar, planejar e executar corretamente os tratamentos, não perdendo de vista a dignidade do paciente e o estado atual da ciência e resguardar o sigilo profissional.

Basicamente, o Conselho Federal de Odontologia, com suas colocações claras, incita e obriga os profissionais a atuarem com atitudes e comportamentos alicerçados no tripé: diagnóstico correto, atualização de conhecimentos científicos e dignidade.

Quando esses valores, somados aos fundamentos da ética e moral são praticados e vivificados de forma diminuta na atividade do cirurgião-dentista, este estará mais exposto e vulnerável a defrontar-se com situações geradoras de riscos e danos para seus pacientes. E porque não dizer, para si próprio também.

Uma grande parte dos processos que atingem tanto os médicos como os dentistas, originam-se em um diagnóstico pobre, insuficiente, por vezes, precoce, sem buscar maiores informações. Em seu artigo $3^{\circ}$, I, o Código de Ética Odontológica constitui como direito fundamental do cirurgiãodentista "diagnosticar, planejar e executar tratamentos, observando o estado atual da ciência e sua dignidade profissional".

Estabelece o Código de Ética Odontológica: Art. $6^{\circ}$. Constitui infração ética: deixar de esclarecer adequadamente os propósitos, riscos, custos e alternativas do tratamento; e iniciar tratamentos em menores sem autorização de seus responsáveis ou representantes legais, exceto em casos de urgência ou emergência.

Freqüentemente, por provocar desgastes profundos às imagens profissionais, além das deficiências técnicas, ou mesmo negligência, imprudência ou imperícia, as deficiências de comunicação entre o profissional e o paciente também devem ser salientadas. Sob este último aspecto, o dentista deverá estar sempre aberto a fornecer ao paciente ou seu responsável as instruções que se fizerem necessárias; os esclarecimentos referentes aos problemas ou dificuldades e ao andamento do tratamento, mantendo, dessa forma, um canal de comunicação e, consequentemente, um bom relacionamento com o próprio paciente ou sua família.

Todos os profissionais deveriam estar cientes que os pacientes ou seus responsáveis têm o direito, como visto acima, de conhecer, detalhadamente, todas as informações, instruções e aconselhamentos referentes ao tratamento.

Atitudes por vezes agressivas e ofensivas de um profissional prepotente, que se julgando superior ao seu paciente e não admitindo que possa vir a cometer eventualmente falhas ou erros, criam um estado de animosidade interpessoal que acaba por dificultar a comunicação, deteriorando dessa forma, o relacionamento harmônico e de amizade que deveria manifestar-se com seus pacientes. Muitas vezes, esses elementos atuam como 
verdadeiros agentes desencadeadores ou estimulantes dos processos contra os dentistas.

O cirurgião-dentista, na elaboração de um diagnóstico, necessitará montar um prontuário completo do paciente, com os exames complementares necessários, exame físico geral e local, além de uma avaliação anamnésica completa e bem elaborada. A somatória e o estudo destes elementos desembocam em um diagnóstico completo que, por sua vez, possibilitará ao cirurgião-dentista elaborar o plano de tratamento e prognóstico adequados. Um prontuário deficiente e incompleto e a falta de autorização e consentimento do paciente ou seu responsável, atestando por escrito e assinando tal documento, podem causar grandes danos. Esses procedimentos bem efetuados estarão esclarecendo os envolvidos na questão sobre a ciência e acordo a respeito de determinado ato profissional, assim..... para que então desta forma se esclareça que os mesmos estão cientes e de acordo com a efetivação de determinado ato profissional, assim como do respectivo orçamento e forma de pagamento.

Portanto, além de diligente no exercício profissional, o dentista deve registrar, por escrito, todos seus atos, advertências dadas ao paciente e colher sua assinatura.

\subsection{Referências ao Código de Defesa do Consumidor}

O Código de Defesa do Consumidor surgiu, na área do direito obrigacional, para inovação, no sentido de se criar novos pensamentos, pretendendo que os fornecedores não tivessem condutas abusivas e nem os consumidores ultrapassassem os seus direitos, objetivando o equilíbrio necessário às relações entre consumidor e fornecedor. $\mathrm{O}$ código de defesa do consumidor é uma norma objetiva, uma lei de ordem Pública e interesse social com características de parcialidade pelos princípios de boa-fé entremeando suas regras. Dentre os profissionais englobados pelo dever de indenizar pelo Código de Defesa do Consumidor, está o cirurgião-dentista, ou seja, fornecedor, definido em seu art $3^{\circ}$ a este cunho, sendo este um profissional liberal, que exerce uma atividade remunerada, incluído neste conceito devido a seu serviço caracterizar- se como relação de consumo, escolhido pelo consumidor "intuitu personae", ou seja, a escolha se baseou em relação de confiança e competência acreditados pelo paciente, este último, destinatário final do serviço prestado, interpretado no artigo $2^{\circ}$ do CDC, para que se caracterize como consumidor.

Para a caracterização do profissional liberal, deve ser feita a diferença entre obrigação de meio e resultado. Quando sua obrigação for de resultado, sua responsabilidade pela relação de consumo é objetiva. Porém, quando se tratar obrigação de meio aplica-se o art 14 $\S 4^{\circ}$, devendo ser enfocada a teoria da culpa, sendo possível ter a inversão do ônus da prova. Conforme o art $6^{\circ}$ inciso VIII do CDC., sobre a publicidade inadequada dos serviços odontológicos, refere-se também o Código de Defesa do Consumidor., com relação à falta de esclarecimentos necessários para que o consumidor se sinta apto a procurar pelo serviço, e a partir daí com suas dúvidas sanadas fazer a melhor opção para o tratamento.

Quando o consumidor sentir-se lesado, prejudicado ou ofendido, ele tem o direito, recorrendo-se a uma legislação específica que o defende e o protege, entrar com uma ação processual contra o referido profissional. E mais, que em decorrência desse processo, caso a justiça reconheça que seus direitos foram realmente ofendidos, ele terá o privilégio de receber uma importância considerável em dinheiro.

Em seu art. $6^{\circ}$, o Código de Defesa do Consumidor vislumbra os direitos do consumidor, garantindo a efetivação de danos morais e patrimoniais, individuais, coletivos e difusos, em seu inciso VI; no artigo 20, ao tratar da questão dos vícios de qualidade do serviço prestado, consta que o consumidor poderá pleitear a reexecução dos serviços, sem custo adicional ou, cabível também, a restituição imediata da quantia paga, sem prejuízo de eventuais perdas e danos e ou abatimento do preço.

Também faz o Código de Defesa do Consumidor alusão à ocorrência de dano sofrido pelo paciente:

Art. 14 - O fornecedor de serviço responde, independentemente da existência de culpa, pela reparação dos danos causados aos consumidores por defeitos relativos à prestação dos serviços, 
bem como por informações insuficientes ou inadequadas sobre sua fruição e riscos.

$\S 3^{\circ}$ I- tendo prestado o serviço, o defeito inexistente;

II- quando a culpa é exclusivamente do consumidor.

$\S 4^{\text {o: }}$ A responsabilidade pessoal dos profissionais liberais será apurada mediante a verificação de culpa.

Entretanto, vale a pena frisar que o cirurgião-dentista não será responsabilizado se o dano causado se der em razão de erro escusável, por culpa exclusiva da vítima, por caso fortuito ou por motivo de força maior. Há que se provar a culpa do profissional liberal e Assim uma prova técnica processualmente não realizada, ou sendo realizada, não comprovar a culpa do profissional, eximindo-o desta situação, configurando nos autos a inexistência de um dever para o cirurgião-dentista de indenizar o paciente por eventual dano que este, porventura, tenha sofrido em seu tratamento, então, cabe ao profissional, apresentar documentos que comprovem a ausência da sua culpa.

Entre o cirurgião-dentista e o seu paciente, por ser uma relação de consumo deve existir um contrato, na figura Prontuário Odontológico. Mas, mesmo sendo uma relação de consumo, a responsabilidade deste profissional, no exercício de sua atividade, é uma responsabilidade subjetiva. $\mathrm{O}$ contrato é essencial porque em sede de uma relação de consumo, terá a finalidade básica de estabelecer normas e parâmetros, regulando a própria relação de prestação de serviço, que se estabelece entre o profissional liberal e seu paciente, quando do início de um tratamento.

O aspecto contratual da relação do cirurgião-dentista com o paciente se finda em uma obrigação contratual para realização do serviço convencionado, que consiste no seu plano de tratamento, que poderá ser considerada cumprida, ou seja, com um resultado final, gerando assim, uma responsabilidade objetiva, pela obrigação de resultado.

Mas certo é que demonstrado que os sofrimentos físicos e morais padecidos por um paciente, após o tratamento odontológico a que foi submetido decorreram de imperícia, negligência ou imprudência do profissional, ficará caracterizado o dever deste de indenizar o mal causado, eis que presente o elemento integrador da responsabilidade civil, a culpa, no seu agir fica, com a presença da culpa, patente o inadimplemento contratual do cirurgião-dentista em sua obrigação de meio para como paciente, cujo objeto jurídico caracteriza-se pelo correto proceder no atendimento a este, ou seja, atuar com diligência, perícia e prudência, dentro dos conhecimentos atualizados da profissão odontológica indicados para aquele local e momento.

Dessa forma, devem os serviços prestados, corresponder às expectativas esperadas por estes, juntamente com as geradas pelo profissional, através de sua propaganda e baseada em suas condutas técnico-científicas.

Contudo, cabe ao cirurgião-dentista, consciente de sua responsabilidade e obrigação inerente à profissão, minimizar sua taxa de risco profissional, assim como evitar ações por parte de seus pacientes, munindo-se de uma série de atenções e cuidados, observando rigorosamente as regras da boa atuação profissional e praticando sistematicamente um relacionamento harmônico e de amizade com seus pacientes.

\subsection{Referências à Constituição Federal}

A Responsabilidade Civil do Cirurgião dentista engloba embasamentos na Constituição Federal, bem como, no Código de Defesa do Consumidor e outras Legislações citadas no presente trabalho, as quais baseiam-se em Fundamentos e Princípios Constitucionais.

A Constituição, em seu art. $5^{\circ}$, caput, vem buscando a igualdade pelo Princípio da isonomia ou da igualdade, "todos são iguais perante a lei”. Não se admite discriminação de qualquer natureza entre qualquer ser humano. Também em seu inciso I, estabelece expressamente que homens e mulheres são iguais em direitos e obrigações, portanto, pressupõe a igualdade entre eles.

$\mathrm{O}$ art. $5^{\circ}$, II, da CRFB/88, baseado no Princípio da Legalidade, dispõe que todos são livres para fazer ou não fazer alguma coisa, salvo o que a lei proíbe; apenas as leis podem limitar a liberdade individual. A liberdade de ação profissional, dá continuidade ao Princípio, no art. 5 XIII; 
que consiste na faculdade de escolha de trabalho que se pretende exercer e para tal exercício, a Constituição estabelece que podem ser feitas certas exigências pela legislação ordinária, sendo que para o exercício da profissão de um Cirurgião Dentista, é necessária a formação do individuo em uma Faculdade de Odontologia legalmente inscrita e reconhecida por órgãos superiores (MEC), juntamente com inscrição do CRO do profissional.

É o direito de cada indivíduo exercer qualquer atividade profissional, de acordo com sua própria vontade, incluindo a tais vontades, os direitos e obrigações de cada um. Perante a Constituição art. 5 XXXV, O estado deve buscar que todos possam gozar dos mesmos direito e Obrigações.

Relacionados à questão processual, verifica-se o Princípio do Juiz Natural (inciso LIII), onde ninguém será sentenciado nem processado senão pela autoridade competente. Este princípio tem por finalidade assegurar o julgamento por um juiz independente e imparcial, porém, na área pertinente à matéria - área civil. O Princípio do Contraditório e da Ampla Defesa art. $5^{\circ}$, LV, assegura a uma das partes, ou seja, a parte contrária, o direito de ser ouvida, pois tem que haver igualdade entre as partes na relação processual. Não se pode admitir provas ilícitas no processo, a prova obtida por meios ilícitos será nula.

Estabelece o texto Constitucional que "ninguém será considerado culpado até o transito em julgado de sentença penal condenatória", pressupõe que antes de um processo condenatório, todos os cidadãos devem ser considerados inocentes. Princípio da presunção de inocência, que veda a adoção de institutos como a presunção de culpa em determinadas situações e a inversão do ônus da prova, inciso LVII.

O Ordenamento Jurídico baseia-se, então, na Constituição, relacionados a seus princípios fundamentais como regras informadoras de todo um sistema de normas, pelos direitos e garantias fundamentais que abrangem a todos os ramos do Direito.

\section{Conclusão}

Os profissionais, ou seja, cirurgiõesdentistas, estão sujeitos aos riscos de responder frente aos legisladores e à sociedade, pelas obrigações e ônus a que eventualmente possam estar sujeitos, decorrentes de prejuízos ocasionados a seus pacientes, quando do exercício de sua atividade profissional.

Após a sanção do Código de Defesa do Consumidor, no enfoque aos erros médicos e odontológicos, vieram orientações mais concretas e direcionadas visando ao direito que o consumidor tem de recorrer, desde então, a uma legislação específica através de uma orientação para a formação da ação processual contra o referido profissional, buscando ressarcimento do dano que, porventura, tenha sofrido.. Pois, por esse Código, é dado ao consumidor uma proteção essencial, uma garantia de efetivação da relação de consumo, a facilidade de sua defesa pela inversão do ônus da prova a seu favor, cabendo ao cirurgião dentista provar que as alegações deste não são verdadeiras.

Fatoscomoesses, extremamentepositivos, necessários e fundamentais para a estruturação de uma sociedade que se encontra em processo de desenvolvimento, tem contribuído para a formação de uma conscientização social de que os profissionais têm deveres bem definidos e a sociedade e direitos que lhe são específicos.

Dessa forma, sobretudo para os profissionais da saúde, ao terem que conviver com uma atividade de risco, não sendo possível descartá-la, ignorá-la ou eliminá-la, “sobra-lhes como saída”, preveni-la, minimizá-la, enfim, criar e desenvolver uma consciência profunda de sua responsabilidade enquanto profissional liberal, procurando desenvolver e praticar em seu ofício, atitudes éticas, comportamentos morais, atualizações científicas constantes, um eficiente e organizado sistema de documentação, um relacionamento amistoso e, por vezes, até caritativo com seus pacientes, estabelecendo uma relação de inteira confiança mediante os serviços prestados para com o paciente e, finalmente, um segmento fiel e ativo às disposições presentes no seu Código de Ética, bem como atenções voltadas também ao Código de defesa do consumidor, observando a extensão jurídica ligada à relação de consumo
Artigo

Original

Original

Paper

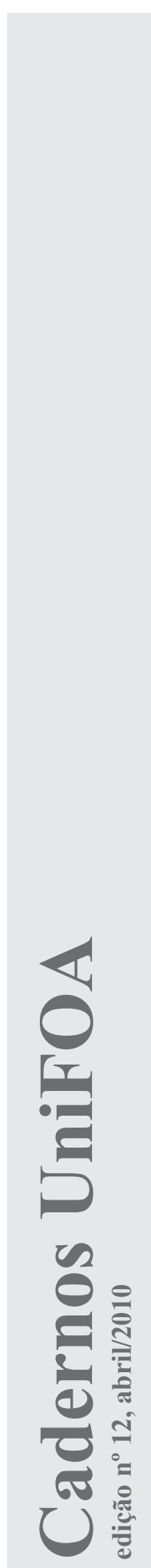


profissional/paciente, para a concretização de contratos de prestação de serviço.

Por fim, há de se frisar também, um correto comportamento do cirurgião-dentista em relação a seus pacientes, verificando sempre a conduta de um bom profissional, além de um excelente ser humano, obedecendo e seguindo os mandamentos ideais para uma prática odontológica perfeita e mais segura. Tendo assim, uma consequência proveitosa e satisfatória do cumprimento de um trabalho bem efetivado. Eximindo-se, então, de uma situação sem qualquer complicação que venha por ventura comprometer o trabalho de um profissional de suma seriedade e competência.

\section{Referências}

BARROS, Washington de. Curso de Direito Civil. Direito Das Obrigações. $2^{\circ}$ parte. 34 ed. São Paulo. 2003.

CAVALIERI, Sergio Filho. Programa de Responsabilidade Civil. $7^{\mathrm{a}}$ ed. Atlas S.A. São Paulo 2007.

FERNANDES F.; CARDOZO H. F. Responsabilidade do Cirurgião Dentista: o pós-tratamento ortodôntico. ABO Nacional. Vol XII, n ${ }^{\text {5 }}$, out/nov. 2004. pp. 298 - 305.

GONÇALVES, Carlos Roberto. Responsabilidade Civil. $2^{\mathrm{a}}$ ed, volume IV. Saraiva. São Paulo. 2007.

PEREIRA, Caio Mario da Silva. Responsabilidade Civil. 9 ed. Rio de Janeiro. Forense, 1998.

Código de Ética Odontológica. 2007.

SILVA A. A.; MALACARNE G. B. Responsabilidade Civil do Dentista perante ao Código de Defesa do Consumidor. Jornal Brasileiro de Ortodontia e Ortopedia Facial. Ano 4, no 22, 1999. pp. $305-310$.

SILVA M da. Compêndio de Odontologia Legal. $1^{\text {a }}$ ed. Rio de Janeiro, Guanabara Koogan S.A., 1997
STOCO, Rui. Responsabilidade Civil e sua Interpretação Jurisprudencial. 4 ${ }^{\mathrm{a}}$ ed. Revista dos Tribunais. São Paulo. 1999.

TOLETO, Antonio Luiz de; WINDT, Márcia Cristina Vaz dos Santos; CÉSPEDES, Livia. Código de Defesa do Consumidor, Código Civil, Constituição Federal. $5^{\circ}$ ed. São Paulo. Saraiva, 2008.
Endereço para Correspondência:

Enio Figueira Junior

efigueira@oi.com.br

Rua Luiz Pereira Graça, 165 -

Esplanada do Cruzeiro - Valença- RJ -

Tel.: (24) 2453-1718

Informações bibliográficas:

Conforme a NBR 6023:2002 da Associacão Brasileira de Normas Técnicas (ABNT), este texto científico publicado em periódico eletrônico deve ser citado da seguinte forma: JUNIOR, Enio Figueira; TRINDADE, Giselle de Oliveira. Responsabilidade do Cirurgião Dentista Frente ao Código de Defesa do Consumidor. Cadernos UniFOA. Volta Redonda, ano V, n. 12, abril 2010. Disponivel em: < http://www.unifoa.edu.br/cadernos/edicao/12/63.pdf> 